\title{
Lauserõhu akustilised korrelaadid eesti keeles
}

\author{
Meelis Mihkla \\ Eesti Keele Instituudi vanemteadur-osakonnajuhataja \\ meelis.mihkla@eki.ee \\ Heete Sahkai \\ Eesti Keele Instituudi teadur \\ heete.sahkai@eki.ee
}

\begin{abstract}
Teesid: Käesoleva uurimuse eesmärk oli tuvastada lauserõhu akustilisi korrelaate eesti keeles. Selleks uuriti erivältelisi testsõnu identsetes lausetes lauserõhulisena ja -rõhutuna. Võimalike korrelaatidena testiti ajalisi tunnuseid ning põhitooni, intensiivsuse, spektri ja vokaalikvaliteediga seotud parameetreid. Hinnati akustiliste parameetrite statistilist olulisust ja nende lauserõhu klassifitseerimisvõimet lineaarse diskriminantanalüüsi põhjal. Lauserõhu akustilisteks korrelaatideks osutusid põhitooni tipu kõrgus ja põhitooni ulatus ning kestus ja intensiivsuse maksimum. Spektraalsete tunnuste ja vokaalikvaliteedi seos lauserõhuga oli marginaalne. Lauserõhu akustilist avaldumist mõjutas ka sõna välde.
\end{abstract}

Märksõnad: eesti keel, intensiivsus kestus, lauserõhk, põhitoon, spektraalne emfaas, vokaali kvaliteet, välde

\section{Sissejuhatus}

Artikli eesmärk on uurida, kuidas avalduvad eesti keeles akustiliselt lauserõhud ehk prosoodiliste fraaside meetriliselt tugevad positsioonid. Lauserõhkude peamine fonoloogiline korrelaat on tooniaktsendid, s.t meetriliselt tugevate ehk prominentsete silpidega seostatud fonoloogilised häälekõrguse tasandid ehk toonid (Asu et al. 2016: 166-167). Eesti keele tooniaktsentide fonoloogiat ja foneetikat on põhjalikult kirjeldanud Eva Liina Asu (2004) ning Eva Liina Asu ja Francis Nolan (2007). Akustiliselt võivad lauserõhud avalduda lisaks põhitoonile ka muude tunnuste, eelkõige kestuse ja intensiivsuse kaudu (Lehiste 1970). Käesolevas uurimuses keskendutaksegi küsimusele, millised on eesti keele lauserõhu akustilised korrelaadid põhitooni kõrval ning kui suur 
on nende panus lauserõhu realiseerumisse. Kaugem eesmärk on võrrelda lauserõhu korrelaate sõnarõhu omadega.

Nii sõna- kui ka lauserõhku seostatakse üldiselt samade akustiliste korrelaatidega, milleks on kestus, intensiivsus, spektri omadused ning rõhulise silbi vokaali spektraalne laienemine (nt Lehiste 1970; van Heuven 2014). Peamiselt või isegi eranditult lauserõhu korrelaadiks on peetud põhitooni (van Heuven 2014), kuid teisalt leiavad Irene Vogel, Angeliki Athanasopoulou ja Nadya Pincus (2016), et põhitoon on peamine sõnarõhu korrelaat kõigis nende uurimuses käsitletud neljas keeles (hispaania, kreeka, ungari ja türgi). Põhitooni seostumine lauserõhuga on siiski ootuspärane eesti keele tüüpi keeltes, kus lauserõhku väljendatakse sõnade pearõhuliste silpidega joondatud tooniaktsentidega (nn head-prominence languages Jun (2005) mõistes).

Eesti keele lauserõhu korrelaatidest on varem põhjalikult uuritud tooniaktsentide foneetikat ja fonoloogiat (Asu 2004) ning kestust (Suomi et al. 2013; Lehiste 1968); samuti on uuritud kontrastiivse ehk emfaatilise lauserõhu ${ }^{1}$ korrelaate (Suomi et al. 2013; Suomi \& Meister 2013; Sahkai et al. 2015).

Olenevalt tooniaktsendi tüübist võib sõna rõhulise silbiga olla joondatud nii kõrge kui ka madal toon, samuti sõltub tooniaktsendi joondumine vältest ning kahest toonist koosnevate aktsentide puhul haarab aktsent enamasti ka rõhulisele silbile järgnevat või eelnevat rõhutut silpi (Asu 2004; Asu et al. 2016); kuna sõnarõhk on eesti keeles valdavalt esimesel silbil, ulatub eelneva tooniga bitonaalne aktsent seega üle sõnapiiri. Uurides põhitooni lauserõhu korrelaadina tuleks seega arvestada tooniaktsendi tüüpi ning sõnarõhku ja väldet.

Kari Suomi, Einar Meister, Riikka Ylitalo ja Lya Meister ( Suomi et al. 2013) võrdlesid segmentide kestusi lauserõhututes, lauserõhulistes ja kontrastiivse lauserõhuga sõnades ning leidsid, et segmentide kestuserinevused lauserõhututes ja lauserõhulistes sõnades ei ole statistiliselt olulised, eristades üksnes kontrastiivse lauserõhuga sõnu ülejäänud kahest kategooriast. Teisalt leidis Ilse Lehiste (1968, 1970), et lauserõhulistes ja -rõhututes sõnades jääb küll samaks rõhulise ja rõhutu silbi kestussuhe, kuid nii rõhulise kui ka rõhutu silbi absoluutne kestus on lauserõhututes sõnades märgatavalt lühem. Viidatud kahes uurimuses saadud erinevaid tulemusi võib seletada lauserõhuliste ja -rõhutute sõnade määramiseks kasutatud erineva metoodikaga. Lehiste (1968) uurimuses jagati uuritud sõnad lauserõhulisteks ja lauserõhututeks kuuldelise hinnangu põhjal. Suomi et al. (2013) uurimuses käsitleti lauserõhutuna tuntud informatsiooni kandvaid sõnu, mis eelnevad kitsale fookusele; metoodika lähtub eeldusest, et tuntud informatsiooni kandvad mittefokaalsed sõnad on alati lauserõhutud. On siiski teada, et primaarsele lauserõhule eelnev tuntud informatsioon ei pruugi olla deaktsentueeritud (vrd nt Rochemont 2016: 45). Tuntud informatsiooni lauserõhulisust eesti keeles primaarsele lauserõhule eelnevas 
positsioonis ehk kitsa fookuse eel on käsitlenud Heete Sahkai ja Meelis Mihkla (2017). Uurimuses jõuti järeldusele, et tuntud informatsiooni kandvad sõnad kitsa fookuse ees on eesti keeles lauserõhulised. Seetõttu käsitleme käesolevas uurimuses lauserõhutuna kitsale fookusele järgnevaid tuntud informatsiooni kandvaid sõnu ning võrdleme testsõna kestust ühelt poolt neutraalses laia fookusega lauses primaarset lauserõhku kandvas positsioonis ja teiselt poolt kitsa fookusega lauses kitsale fookusele järgnevas positsioonis.

Kestus osutus oluliseks kontrastiivse/emfaatilise lauserõhu tunnuseks nii Suomi, E. ja L. Meistri ja Ylitalo (2013) kui ka Sahkai, Mihkla ja Kalviku (2015) uurimuses. Viimases osutus emfaasi korrelaadiks lisaks ka intensiivsus, kuigi tunduvalt vähem oluliseks kui kestus. Erinevalt paljudest teistest keeltest ei avaldunud emfaas aga põhitoonis (nagu leidis ka Salveste 2015), s.t emfaatilise lauserõhuga sõna (kitsas fookus) on realiseeritud pikemana ja suurema intensiivsusega, kuid mitte kõrgema põhitooniga või suurema põhitooni ulatusega kui mitte-emfaatilise lauserõhuga sõna (primaarset lauserõhku kandev sõna laia fookusega lauses).

Rõhuliste üksuste vokaale on sageli kirjeldatud puhaste ja selgetena (formantruumis spektraalselt laienenutena), mis peegeldab suuremat artikulatoorset pingutust ja täpsust (van Heuven 2014). Eesti vokaalide kvaliteeti on uuritud väldete kontekstis sõna rõhulistes ja rõhuta silpides (Eek \& Meister 1998; Lippus et al. 2013). Arvo Eegi ja Einar Meistri uurimuses tõdeti, et formantide variatsioonid erinevates jalatasandi vokaalides ei ületa ühte barki ega ole seetõttu tajutavad. Pärtel Lippus, Eva Liina Asu, Pire Teras ja Tuuli Tuisk (2013) tuvastasid, et vokaalikvaliteet ei ole seotud jalatasandi vältega, vaid segmentaalse kestusega.

Üheks prominentsi ja rõhulisuse indikaatoriks on välja pakutud ka spektraalset emfaasi (Sluijter \& van Heuven 1996; Tamburini 2003). Selle parameeteriga mõõdetakse vokaalide energiat teatud spektri sagedusribas, mida normeeritakse kogu spektri energiaga. Eesti keeles on uuritud spektraalse emfaasi seost sõnarõhuga, kuid otsest korrelatsiooni ei leitud (Lippus et al. 2014).

Käesolevas uurimuses kontrollime järgmisi hüpoteese:

1. lauserõhulise sõna F0 tipp on kõrgemal kui lauserõhutul sõnal ja F0 ulatus on suurem (langeva ehk $\mathrm{H}^{*} \mathrm{~L}$ tooniaktsendiga realiseeritud testsõnades);

2. lauserõhulises positsioonis olev sõna on pikem;

3. lauserõhulise testsõna intensiivsuse ulatus ja tase on suurem;

4. lauserõhulise sõna rõhulise silbi vokaalis toimub spektraalne laienemine;

5. lauserõhk mõjutab oluliselt testsõna rõhulise silbi vokaali spektraalset emfaasi;

6. testsõnade akustilistele parameetritele toimib lauserõhu ja sõnaprosoodia (väldete) koosmõju, s.t lauserõhk võib realiseeruda pisut erinevalt olenevalt sõna vältest. 


\section{Andmestik ja meetod}

Andmestik koosneb 18 neljasõnalisest lausest, mis on ette loetud üheksa keelejuhi poolt (viis naist ja neli meest) vastuseks kolmele küsimusele, mis tingivad kolm erinevat infostruktuuri. Näiteks lause "Leena pani lina vanni", kus testsõna on "lina", loeti ette vastusena küsimustele "Mis toimub?" (lai fookus, lauserõhuline tingimus), "Kes pani lina vanni?" (kitsas fookus alusel, lauserõhutu tingimus) ning "Mille Leena vanni pani?" (kitsas fookus sihitisel, mis tingib emfaatilise lauserõhu; seda tingimust kasutati andmestiku normaliseerimise otstarbel ${ }^{2}$ ). Esimest kahte tingimust on illustreeritud joonisel 1. Kokku salvestati 486 lauset. Uuritav sõna asub lauses alati eelviimasel positsioonil, et vältida prosoodiliste piiride mõju. Testsõnadeks on kolm vokaalikeskset ja kolm konsonandikeskset vältekolmikut (tabel 1).

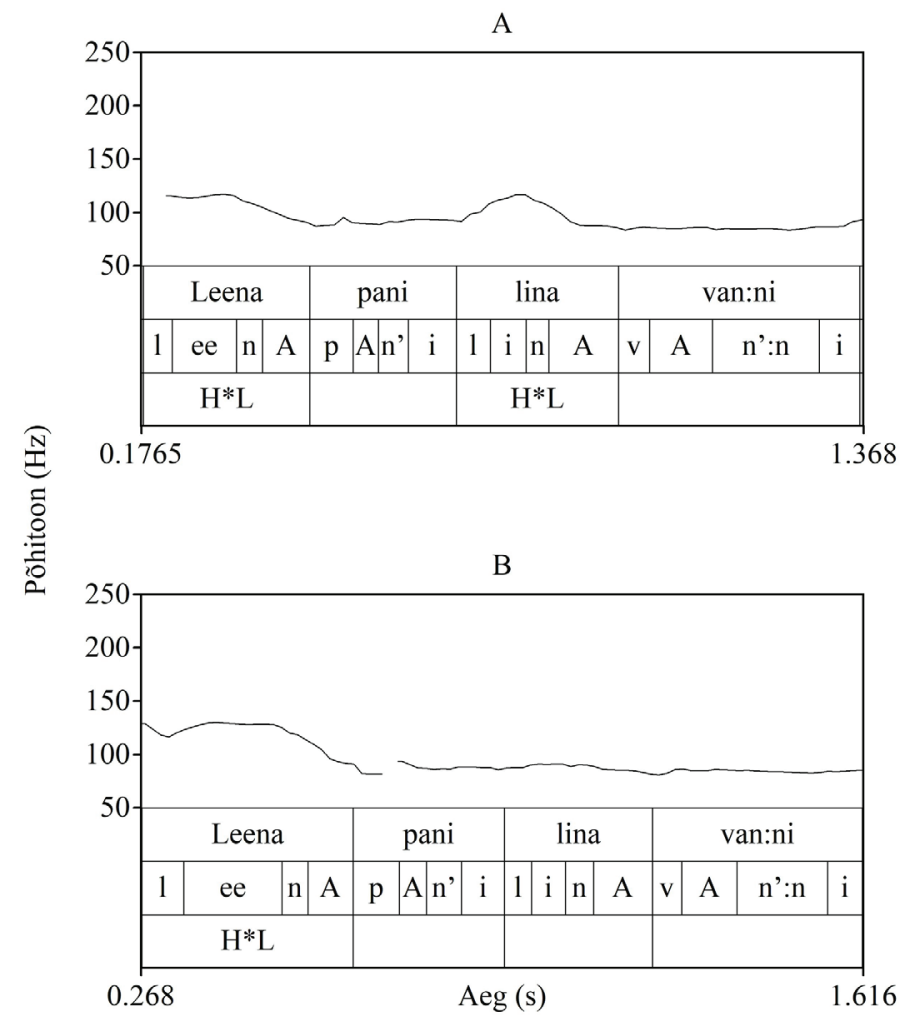

Joonis 1. Testlause "Leena pani lina vanni" loetuna sama kõneleja poolt vastuseks küsimustele "Mis toimub? "(A; testsõna "lina” kannab primaarset lauserõhku) ja "Kes pani lina vanni?” (B; testsõna on lauserõhutu). 
Tabel 1. Katses kasutatud sihtsõnad vältekategooriate ja-astmete kaupa.

\begin{tabular}{|c|c|c|c|c|c|}
\hline \multicolumn{3}{|c|}{ Vokaalvältelised } & \multicolumn{3}{c|}{ Konsonantvältelised } \\
\hline Q1 & Q2 & Q3 & Q1 & Q2 & Q3 \\
\hline lina & Liina & vii:na & linu & linnu & lin:nu \\
\hline vene & seene & vee:ne & nõme & Nõmme & nõm:me \\
\hline valu & vaalu & vaa:lu & male & Malle & Mal:le \\
\hline
\end{tabular}

Põhitooni parameetritest ${ }^{3}$ kasutasime analüüsil põhitooni ulatust testsõnas ja testsõna põhitooni tipu suhtelist kõrgust. Põhitooni ulatus testsõnas oli defineeritud rõhulise silbi vokaali põhitooni maksimumi ja rõhuta silbi vokaali põhitooni miinimumi erinevusena. Testsõna põhitooni tipu suhtelise kõrguse määramiseks arvutasime kõigepealt iga keelejuhi andmestikus iga testsõna keskmise F0 maksimumi kolmes katsetingimuses. Testsõna suhteline tipu kõrgus konkreetses katsetingimuses arvutati erinevusena keskmisest väärtusest. Põhitooniandmed teisendati pooltoonidesse, et nais- ja meeskeelejuhtide andmestik oleks paremini võrreldav.

Ajalistest tunnustest oli vaatluse all testsõna suhteline pikenemine-lühenemine eri katsetingimustes. Eelnevalt arvutasime iga testsõna keskmise kestuse kolmes katsetingimuses; testsõna suhteliselt pikenes, kui selle kestus konkreetses tingimuses oli keskmisest väärtusest suurem, ning suhteliselt lühenes, kui reaalne kestus oli keskmisest väiksem.

Intensiivsuse analüüsil kasutasime tunnustena intensiivsuse ulatust testsõnas ja kõnesignaali intensiivsuse taseme suhtelist muutust testsõnas sõltuvalt lauserõhust. Intensiivsuse ulatuse arvutamiseks mõõtsime testsõna keskmist intensiivsust rõhulise silbi vokaalis ja rõhuta silbi vokaalis ning intensiivsuse ulatus kajastas nende mõõtmiste vahet. Intensiivsuse taseme suhtelise muutuse määramiseks testsõnades sõltuvalt lauserõhust arvutasime jälle intensiivsuse maksimumi keskmise väärtuse kolme katsetingimuse põhjal ning intensiivsuse taseme suhtelist muutust lauserõhu tingimustest sõltuvalt käsitlesime kui erinevust keskmisest väärtusest.

Vokaalide võimaliku spektraalse laienemise tuvastamiseks lauserõhu korral mõõtsime esimese kahe formandi väärtusi F1 ja F2 testsõna rõhulise ja rõhuta silbi vokaalides. Formantide väärtused esitati barkides ja saadud andmeid analüüsiti ning kujutati F1-F2 formantruumis mees- ja naiskeelejuhtide kohta eraldi, kuna meeste ja naiste kõnetraktid on füsioloogiliselt erinevate mõõtmetega ja formantide väärtused erinevad.

Spektraalse emfaasi parameetri väärtuste arvutamiseks mõõdeti testsõna rõhulise silbi vokaali spektraalset energiat sagedusribas $500-2000 \mathrm{~Hz}$, saadud energia väärtust normeeriti kogu spektri energiaga. 
Lauserõhu ja sõnaprosoodia koosmõju tuvastamiseks arvestasime analüüsil ka testsõnade välteid.

Kogu kõnematerjal märgendati ja segmenteeriti käsitsi Praat keskkonnas. Akustiliste parameetrite väärtuste mõõtmiseks ja arvutamiseks kasutati Praati skripte. Andmete statistiline analüüs tehti Systat programmipaketiga. Akustiliste parameetrite panust ja klassifitseerimisvõimet lauserõhu määramisel hindasime diskriminantanalüüsi abil.

\section{Tulemused}

\section{Testsõna pikenemine-lühenemine}

Joonise 2 karpdiagrammidel on toodud testsõna kestuste erinevuste jaotused lauserõhulistes ja lauserõhuta positsioonides. Joonise 2a põhjal on lauserõhulised sõnad keskmiselt 39,7 ms pikemad kui lauserõhuta sõnad ja see pikkuse erinevus on statistiliselt oluline $(\mathrm{p}<0,0005 ; \mathrm{F}[1,323]=135,15)$. Kas ja mil määral lauserõhuliste sõnade pikenemine sõltub sõnaprosoodiast e väldetest, on kujutatud joonisel $2 \mathrm{~b}$. Joonise $2 \mathrm{~b}$ põhjal võib väita, et kolmandavältelised lauserõhulised testsõnad pikenevad teistest enam: esmavältelised testsõnad pikenevad keskmiselt 32,4 ms, teisevältelised 30,4 ms ja kolmandavältelised 56,1 ms. Testsõnade keskmised pikkused välteti on ka pisut erinevad (vastavalt $315,8 \mathrm{~ms}, 362,2 \mathrm{~ms}$ ja $381,3 \mathrm{~ms}$ ). Normeerides lauserõhust tingitud sõnade pikenemisi sõnade keskmiste pikkustega välteti võib öelda, et suhteliselt pikenevad kolmandavältelised sõnad teistest rohkem - 14,7\%; teisevältelised sõnad pikenevad 8,4\% ja esmavältelised 10,2\%. Lauserõhu ja sõnaprosoodia (väldete) koosmõju testsõna pikenemisele on ka statistiliselt tõestatav ( $\mathrm{p}=$ 0,$0027 ; \mathrm{F}[5,319]=6,02$ ).
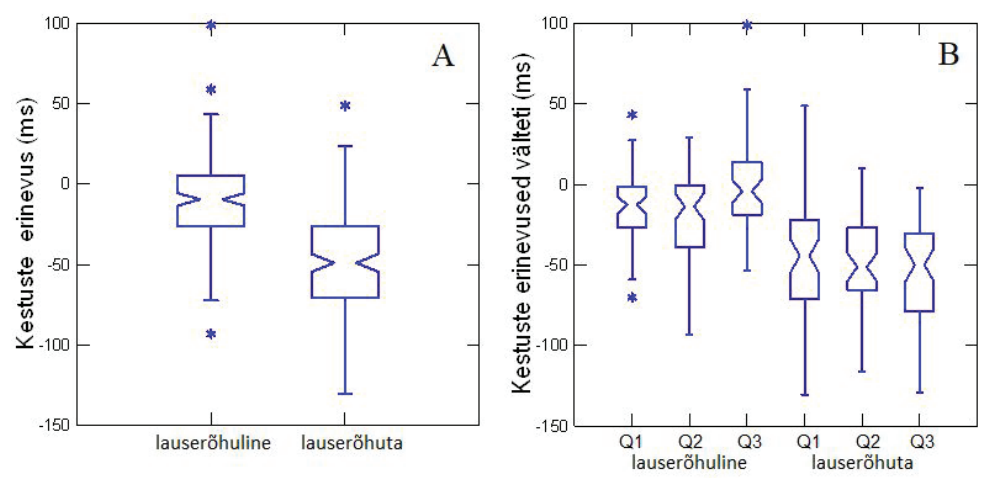

Joonis 2. Karpdiagrammid testsõnade kestuste erinevustest ${ }^{4}$ lauserõhulises ja lauserõhutus tingimuses kõigi sõnade lõikes (a) ja väldete kaupa (b). 


\section{Põhitoon}

Joonisel 3 on kujutatud põhitooni ulatuse ja testsõna põhitoonimaksimumide erinevuste jaotused sõnade lauserõhuliste ja lauserõhuta tingimuste korral. Joonisel 3a on näha, et põhitooni ulatus lauserõhuta testsõnades on suure hulga erimite arvuga, millest mitmed ületavad ka alumist ja ülemist kvartiili. Lauserõhuta andmete suuremale hajuvusele vaatamata on F0 ulatuste erinevused testsõnades statistiliselt olulised ( $\mathrm{p}<0,0005 ; \mathrm{F}[1,284]=87,77$ ) ning lauserõhulistes testsõnades on põhitooni ulatused keskmiselt 2,4 pooltooni suuremad kui lauserõhuta sõnades. Veelgi selgemini avalduvad lauserõhust tingitud erinevused sõnade F0 tipu kõrgustes (joonis 3b). Lauserõhulistes sõnades on põhitooni maksimumid keskmiselt 2,8 pooltooni kõrgemad kui lauserõhuta sõnades, ning see erinevus on oluline ( $\mathrm{p}<0,0005 ; \mathrm{F}[1,224]=324,27)$.
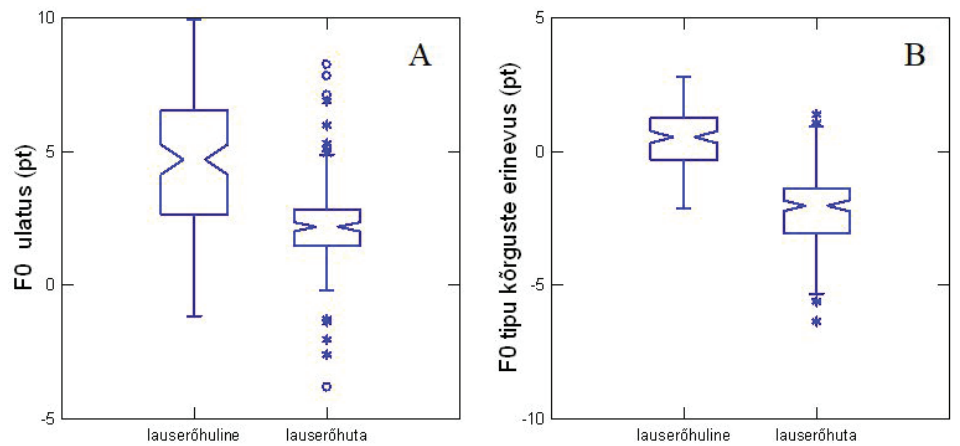

Joonis 3. Testsõna põhitooni ulatuse ja põhitooni tipu kõrguste erinevuste jaotused lauserõhutus ja lauserõhulises tingimuses. Vertikaaltelje nullpunkt vastab kolme katsetingimuse põhjal saadud keskmisele väärtusele.

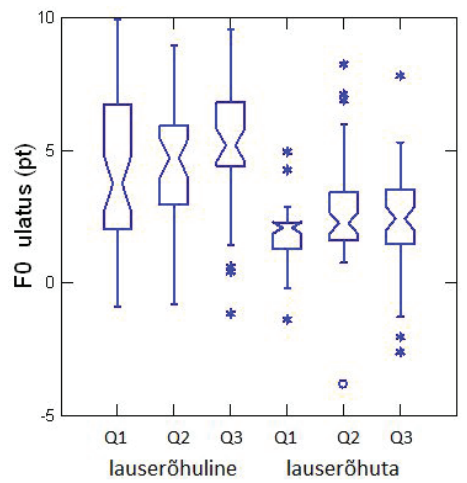

Joonis 4. Testsõnade FO ulatuste jaotused välteti lauserõhulistes ja lauserõhuta testsõnades. 
Joonise 4 karpdiagrammil on toodud F0 ulatuse erinevused lauserõhulistes ja lauserõhuta tingimustes erinevas vältes testsõnade korral. Kõige suurem on F0 ulatuse erinevus kolmandavältelistes sõnades, 2,78 pt, esmavältelistes sõnades on erinevus 2,34 pt ja väikseim on põhitooni ulatuse erinevus teisevältelistes sõnades, 2,06 pt. Ehkki F0 ulatuse erinevused on olulised nii lauserõhust tingituna $(\mathrm{p}<0,0005 ; \mathrm{F}[1,284]=87,77)$ kui ka välteti $(\mathrm{p}<0,0193 ; \mathrm{F}[1,284]=$ 4,03 ), ei saa lauserõhu ja testsõna välte koosmõju põhitooni ulatusele meie andmestiku põhjal siiski tõestada $(\mathrm{p}=0,54474 ; \mathrm{F}[5,280]=0,61)$.

\section{Intensiivsus}

Joonisel 5 on toodud kõne intensiivsusega seotud tunnuste jaotused: intensiivsuse ulatus testsõnas ning intensiivsuse maksimumtaseme erinevused lauserõhulistes ja lauserõhututes testsõnades. Kõne intensiivsuse ulatus testsõnas ei ole lauserõhu korral statistiliselt oluline tunnus ( $\mathrm{p}=0,4626 ; \mathrm{F}[1,323]=$ 0,46), küll aga on intensiivsuse maksimumtasemed lauserõhulistes testsõnades keskmiselt 2,4 dB kõrgemad kui lauserõhututes sõnades, ja see erinevus on oluline $(\mathrm{p}<0,0005 ; \mathrm{F}[1,323]=131,02)$. Analüüsisime ka lause- ja sõnaprosoodiliste tunnuste koosmõju, tuvastades, et testsõna rõhulisuse ja välte koosmõju intensiivsuse taseme tõusule testsõnas on statistiliselt oluline ( $\mathrm{p}=0,0026$; $\mathrm{F}[5,319]=6,06)$.
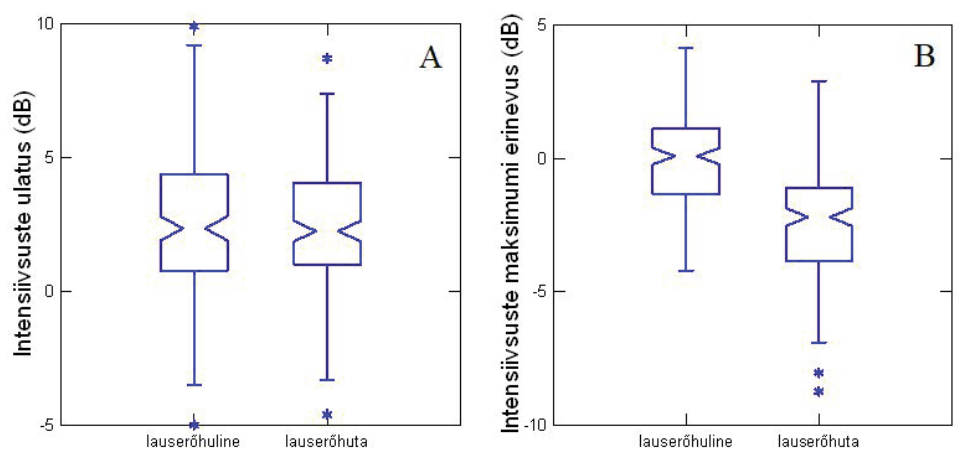

Joonis 5. Testsõna intensiivsuse ulatuse ja harja kõrguse erinevuse jaotused erinevates lauserõhu tingimustes. 


\section{Vokaalid formantruumis ja spektraalne emfaas}

Joonistel 6 ja 7 on esitatud keelejuhtide rõhulise silbi vokaalide kahe esimese formandi keskmised väärtused formantruumi kujunditena, mille tippudes on vastavad vokaalid. Andmed on esitatud välteti ja lauserõhu tingimusena (pidev joon lauserõhuliste ja katkendlik lauserõhutute sõnade korral). Jooniste visuaalsel hindamisel ja andmete statistilisel analüüsil ei täheldatud vokaali formantide spektraalset laienemist lauserõhust tingituna ei mees- ega naiskeelejuhtide puhul. Vokaalide formantruumi graafiline esitus võinuks olla veelgi avaram ja representatiivsem, kui testsõnades oleks eesti keele keskkõrge vokaali $\tilde{o}$ asemel kasutatud kõrget vokaali $u$, aga vokaalide spektraalset laienemist formantruumis sõltuvalt lauserõhu tingimusest see vaevalt oleks esile toonud. Ka testsõna rõhuta silbi vokaalide puhul analüüs spektraalset laienemist ei tuvastanud. Samuti ei ilmnenud olulisi erinevusi väldete vahel ega ka lauserõhu ja väldete koosmõju F1 ja F2 formantidele.
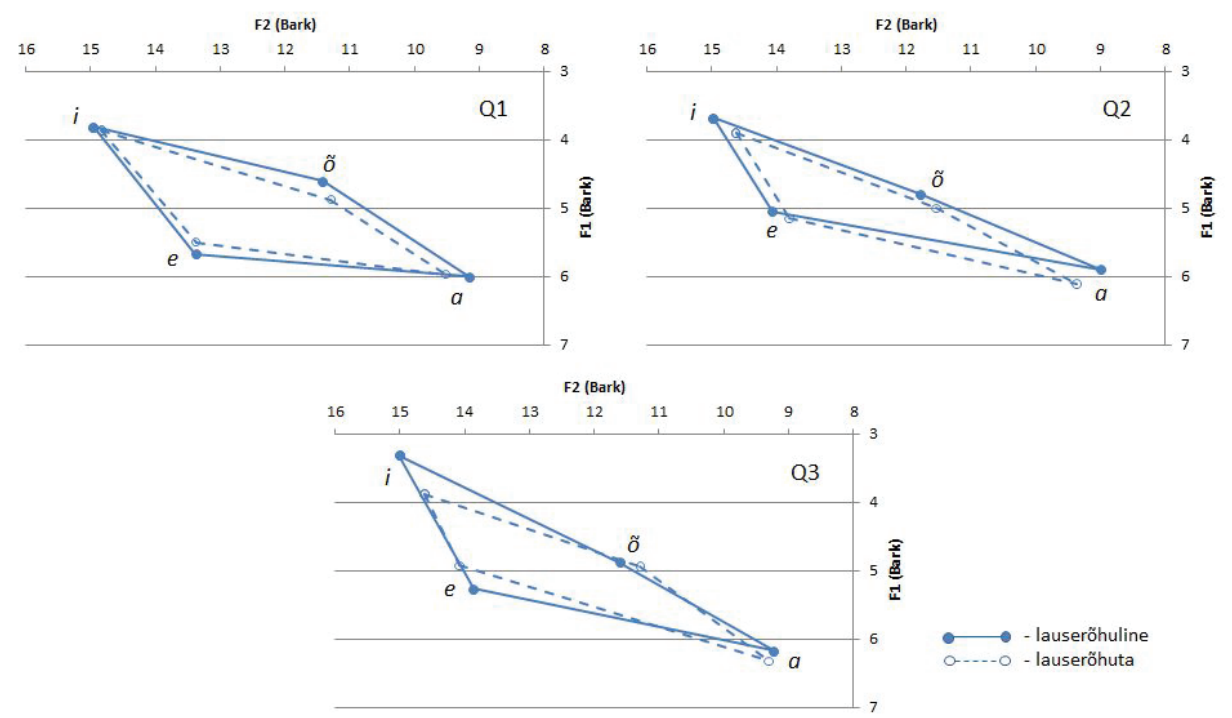

Joonis 6. Naiskeelejuhtide testsõnade rõhulise silbi vokaalid F1-F2 vokaalruumis lauserõhu ja välte tingimuste põhjal. 

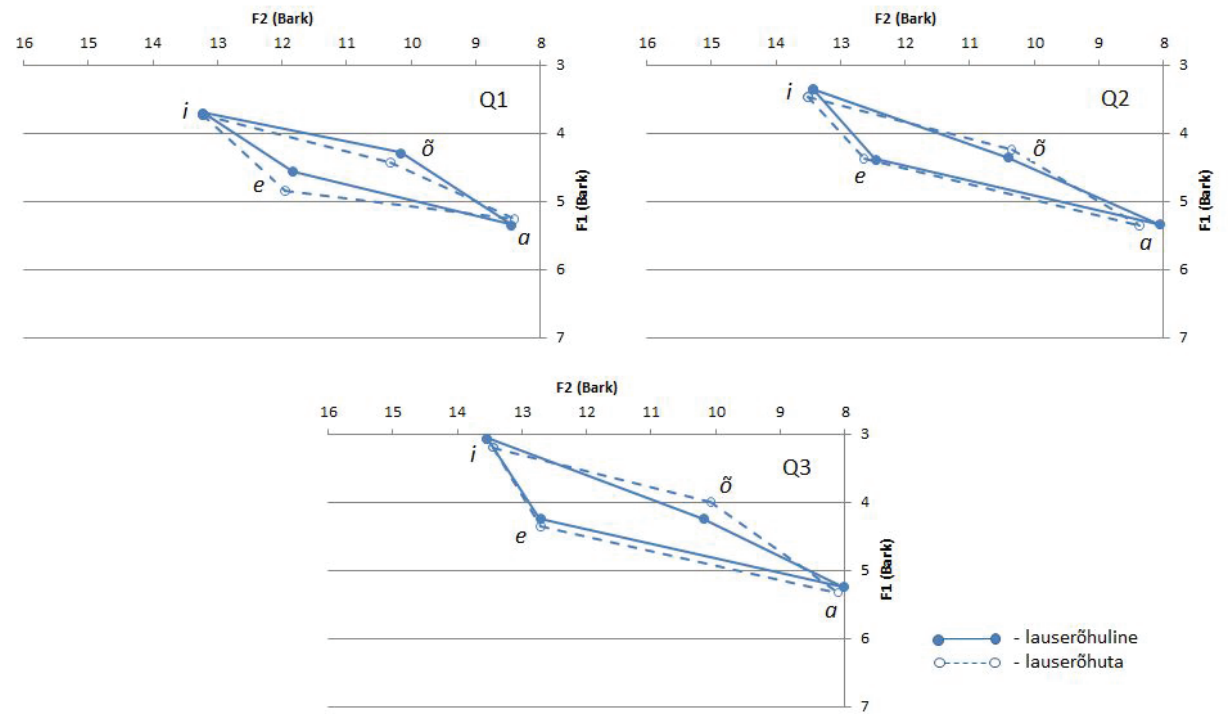

Joonis 7. Meeskeelejuhtide testsõnade rõhulise silbi vokaalid F1-F2 vokaalruumis lauserõhu ja välte tingimuste põhjal.

Joonisel 8 on näha, et energiamuutuste jaotusi testsõnade rõhulise silbi vokaali sagedusribas 500-2000 Hz lauserõhulisus peaaegu ei mõjuta ( $\mathrm{p}=0,3619$; $\mathrm{F}[1,323]=0,83)$. Katsetasime analüüsil energia mõõtmisi ka erinevates sagedusribades, aga lauserõhulisusega see parameeter ei korreleerunud.

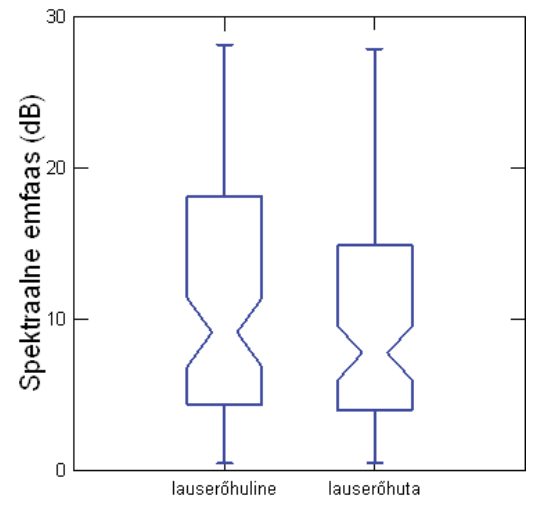

Joonis 8. Spektraalne emfaas testsõnade rõhulise silbi vokaalis lauserõhulises ja lauserõhutus tingimuses. 


\section{Lauserõhulisuse akustiliste korrelaatide klassifitseerimisvõime}

Selleks, et hinnata akustiliste parameetrite panust ja klassifitseerimisvõimet lauserõhu määramisel, kasutasime lineaarset diskriminantanalüüsi. Tabelis 2 on toodud erinevate akustiliste korrelaatide panused (protsentides) lauserõhu tuvastamisel.

Tabel 2. Akustiliste korrelaatide klassifitseerimisvõime lineaarse diskriminantanalü̈̈si põhjal.

\begin{tabular}{|c|}
\hline $\begin{array}{c}\text { Lauserõhu tuvastus } \\
\text { (juhuslikkuse piir 50\%) }\end{array}$ \\
\hline Põhitooni tipu kõrguste erinevus 89\% \\
\hline Põhitooni ulatus 76\% \\
\hline Kestuste erinevus 75\% \\
\hline Intensiivsuse tasemete erinevus 73\% \\
\hline F1 \& F2 rõhulise silbi vokaal 62\% \\
\hline F1 \& F2 rõhuta silbi vokaal 53\% \\
\hline Spektraalne emfaas 52\% \\
\hline
\end{tabular}

Lauserõhu tuvastamisel on parim klassifitseerimisvõime (89\%) põhitooni tipu kõrguste erinevusel. Mõõdukalt headeks lauserõhu korrelaatideks on ka põhitooni ulatus (76\%), kestuste erinevus (75\%) ja intensiivsuse tasemete erinevus (73\%). Testsõna rõhulise ja rõhuta silbi vokaalide kvaliteet (spektraalne laienemine) ning spektraalne emfaas lauserõhuga ei korreleeru, kuna panused lauserõhu tuvastamisse on juhuslikkuse piirile väga lähedal. 


\section{Arutelu}

Uurimuses vaadeldud akustilistest parameetritest korreleerus lauserõhuga kõige tugevamini põhitoon, mis on ootuspärane, võttes arvesse, et lauserõhu fonoloogilisteks korrelaatideks on tooniaktsendid: $\mathrm{H} * \mathrm{~L}$ tooniaktsendiga lauserõhulise sõna F0 tipp on kõrgemal kui lauserõhutul sõnal ja F0 ulatus on suurem. Sealjuures osutus neist kahest tunnusest tugevamaks F0 tipu kõrgus, mis oli üldse kõige tugevam lauserõhu korrelaat, andes klassifitseerimistulemuseks 89\%. Põhitooni ulatuse klassifitseerimisvõime küündis 76 protsendini.

Küllaltki oluliseks lauserõhu korrelaadiks põhitooni tunnuste kõrval osutus kestus, klassifitseerides õigesti $75 \%$ andmetest. See tulemus on kooskõlas Lehiste (1968) tulemusega, kuid mitte Suomi et al. (2013) tulemusega. Erinevus tuleneb ilmselt sellest, et viimases uurimuses käsitleti lauserõhutu tingimusena fookuse-eelset positsiooni, mis võib eesti keeles olla lauserõhuline (Sahkai \& Mihkla 2017). Asjaolu, et kestus osutus eesti keeles niivõrd oluliseks lauserõhu tunnuseks, võib pidada mõnevõrra ootuspäratuks funktsionaalse koormuse hüpoteesi (ingl k functional load hypothesis) valguses, mille kohaselt keeles suurt funktsionaalset koormust kandvad tunnused ei ole mõjutatud muudest grammatilistest protsessidest (hüpoteesi ajaloo ja rakendamise kohta sõnarõhualastes uurimustes vt Vogel et al. 2016). Näiteks ennustavad Irene Vogel, Angeliki Athanasopoulou ja Nadya Pincus (2016) funktsionaalse koormuse hüpoteesist lähtudes, et häälikute tasandil kontrastiivselt toimivad omadused (nagu pikk versus lühike) ei ole peamised sõna- ja lauserõhu tunnused, ning et sõnarõhu peamised tunnused ei lange kokku lauserõhu omadega. Sarnaselt seletavad oma uurimistulemusi Kari Suomi, Einar Meister, Riikka Ylitalo ja Lya Meister (2013), kes ei leidnud seost kestuse ja lauserõhu vahel; täpsemalt pakuvad nad välja tööhüpoteesi, et ainult kontrastiivse lauserõhuga sõnade pikenemine võib olla eriomane täiemõõdulistele kvantiteedikeeltele, kus kvantiteedil on eristav funktsioon nii vokaalide kui ka konsonantide tasandil, mis piirab kestuse varieerumist rõhu korrelaadina. Ühe võimaliku seletuse sellele, miks kestus saab eesti keeles kanda nii suurt funktsionaalset koormat - sõnavälde, lauserõhk, emfaatiline lauserõhk -, pakuvad Juraj Šimko, Daniel Aalto, Pärtel Lippus, Martin Włodarczakja Martti Vainio (2015) uurimistulemused, mille kohaselt eesti keele kõnelejad on kestuse suhtes tundlikumad. Võimalik seletus võiks olla ka see, et sõna tasandil on oluline eelkõige kestussuhe, lause tasandil aga absoluutne kestus.

Mõõdukalt oluliseks lauserõhu korrelaadiks osutus ka intensiivsuse maksimumi tase testsõnas, selle parameetri alusel oli lauserõhu tuvastamise võime $73 \%$. Kolme esimese hüpoteesi realiseerumine annab tunnistust sellest, et ka eesti keeles ei ole lauserõhk seotud vaid ühe akustilise tunnusega, vaid korreleerub mitmetega. 
Neljas püstitatud hüpotees taandus nullhüpoteesiks: vokaalide laienemist testsõna lauserõhu korral F1-F2 formantruumis ei täheldatud. Sisukaks hüpoteesiks ei osutunud ka viies oletus: spektraalne emfaas lauserõhku testsõna rõhulise silbi vokaalis ei markeeri. Analoogilisele tulemusele jõudsid ka Pärtel Lippus, Eva Liina Asu ja Mari-Liis Kalvik (2014) sõnarõhu akustilisi korrelaate uurides. Võib-olla tasuks spektrit iseloomustavate tunnuste valikul emfaasi asemel uurida pigem spektri kaldega seotud parameetreid (vrd nt Kakouros et al. 2017).

Lause- ja sõnaprosoodia seostest täheldasime lauserõhu ja väldete koosmõju testsõna pikenemisele ja kõnesignaali intensiivsuse maksimaalse taseme tõusule: kolmandas vältes lauserõhulistes sõnades oli pikenemine ja intensiivsuse tõus suurim. See viitab sellele, et sõna prosoodiline struktuur mõjutab ka fraasi tasandi kategooriate akustilist avaldumist.

\section{Kokkuvõte}

Lauserõhu akustilisteks korrelaatideks osutusid põhitooni tipu kõrgus ja põhitooni ulatus sõnas ning kestus ja intensiivsuse maksimum. Põhitooni ja intensiivsuse korreleerumist lauserõhuga võib pidada ootuspäraseks, kuid pikenemise olulisus on funktsionaalse koormuse hüpoteesi seisukohalt ootuspäratum. Lauserõhu akustilist avaldumist mõjutas ka sõna prosoodiline struktuur: pikenemine ja intensiivsuse taseme tõus olid suurimad kolmandavältelistes sõnades. Vokaalikvaliteedi ja spektraalse emfaasi seos lauserõhuga oli mitteoluline.

\section{Tänusõnad}

Kirjutise valmimist on toetanud Euroopa Liit Euroopa Regionaalarengu Fondi kaudu (Eesti-uuringute Tippkeskus, TK - CEES), samuti on see seotud Eesti Haridus- ja Teadusministeeriumi uurimisprojektiga IUT 35-1.

\section{Kommentaarid}

1 Emfaatilise lauserõhu abil väljendatakse kitsast ja kontrastiivset fookust; nende kahe kategooria vahel ei ole eesti keeles akustilist erinevust leitud (Salveste 2015; Sahkai et al. 2013, 2014).

${ }^{2}$ Kuigi uurimuses võrreldakse üksnes lauserõhulist ja lauserõhutut tingimust, kasutasime normaliseerimisel ka emfaatilise lauserõhuga tingimust, mille andmed on salvestatud sama eksperimendi käigus. Eeldasime, et mida suurema andmemahu peal normaliseerimine toimub, seda usaldusväärsem on võrdlusbaas teisendusprotsessiks. 
${ }^{3}$ Põhitooni parameetrite analüüsil piirdusime vaid nende testsõnadega, mida keelejuht oli lauserõhulises tingimuses realiseerinud langeva ehk $\mathrm{H}^{*} \mathrm{~L}$ tooniaktsendiga. See kitsendus vähendas küll $12 \%$ andmete hulka, aga tagas adekvaatse võrdlusbaasi.

4 Joonise 2 karpdiagrammide mediaanväärtused on allpool nullväärtust (negatiivsed), kuna andmete normaliseerimist tehti laiendatud andmehulgal, mis sisaldas ka kolmanda katsetingimuse (emfaatiline lauserõhk) salvestisi, mille testsõnad olid keskmisest väärtusest pikemad.

\section{Kirjandus}

Asu, Eva Liina 2004. The phonetics and phonology of Estonian intonation. Doktoritöö. University of Cambridge.

Asu, Eva Liina \& Lippus, Pärtel \& Pajusalu, Karl \& Teras, Pire 2016. Eesti keele hääldus. Tartu: Tartu Ülikooli Kirjastus.

Asu, Eva Liina \& Nolan, Francis 2007. The Analysis of Low Accentuation in Estonian. Language and Speech 50 (4), lk 567-588 (doi: 10.1177/00238309070500040401).

Eek, Arvo \& Meister, Einar 1998. Quality of standard Estonian vowels in stressed and unstressed syllables of the feet in three distinctive quantity degrees. Linguistica Uralica 34 (3), lk 226-233.

Heuven Vincent J. van 2014. Acoustic correlates and perceptual cues of word and sentence stress: Mainly English and Dutch. Gussenhoven, Carlo \& Chen, Yiya \& Dediu, Dan (toim). The 4th International Symposium on Tonal Aspects of Languages, Nijmegen, The Netherlands, May 13-16, 2014. Baixas (FR): International Speech Communication Association ISCA, lk 211-217.

Jun, Sun-Ah 2005. Prosodic typology. Jun, Sun-Ah (toim). Prosodic Typology. The Phonology of Intonation and Phrasing. Oxford: Oxford University Press, lk 430-458 (doi: 10.1093/acprof:oso/9780199249633.003.0016).

Kakouros, Sofoklis \& Räsänen, Okko \& Alku, Paavo 2017. Evaluation of Spectral Tilt Measures for Sentence Prominence Under Different Noise Conditions. Interspeech 2017: Situated Interaction, August 20-24, 2017, Stockholm, Sweden. Proceedings. Stockholm: International Speech Communication Association, lk 3211-3215 (doi: 10.21437/ Interspeech.2017-1237).

Lehiste, Ilse 1968. Vowel quantity in word and utterance in Estonian. Congressus Secundus Internationalis Fenno-Ugristarum Helsingiae habitus 23.-28. VII 1965. Helsinki: Societas Finno-Ugrica, lk 293-303.

Lehiste, Ilse 1970. Suprasegmentals. Cambridge \& London: The M.I.T. Press.

Lippus, Pärtel \& Asu, Eva Liina \& Teras, Pire \& Tuisk, Tuuli 2013. Quantity-related variation of duration, pitch and vowel quality in spontaneous Estonian. Journal of Phonetics 41 (1), lk 17-28 (doi: 10.1016/j.wocn.2012.09.005).

Lippus, Pärtel \& Asu, Eva Liina \& Kalvik, Mari-Liis 2014. An acoustic study of Estonian word stress. Campbell, Nick \& Gibbon, Dafydd \& Hirst, Daniel (toim). Social and 
Linguistic Speech Prosody. Proceedings of the 7th international conference on Speech Prosody. Dublin: International Speech Communications Association, lk 232-235.

Rochemont, Michael 2016. Givenness. Féry, Caroline \& Ishihara, Shinichiro (toim). The Oxford Handbook of Information Structure. New York: Oxford University Press, lk 41-63.

Sahkai, Heete \& Kalvik, Mari-Liis \& Mihkla, Meelis 2013. Prosody of contrastive focus in Estonian. Proceedings of Interspeech 2013: 14th Annual Conference of the International Speech Communication Association, Lyon, France, August 25-29, 2013, lk 315-319.

Sahkai, Heete \& Kalvik, Mari-Liis \& Mihkla, Meelis 2014. Perception of focus size and focus type in Estonian. Jähi, Katri \& Taimi, Laura (toim). XXVIII Fonetiikan päivät. Turku 25.-26. lokakuuta 2013. Konferenssijulkaisu. Turku: Turun yliopisto, lk 72-79.

Sahkai, Heete \& Mihkla, Meelis \& Kalvik, Mari-Liis 2015. Emfaas ja fookus eesti keeles. Eesti ja Soome-ugri Keeleteaduse Ajakiri 6 (3), lk 97-122 (doi: 10.12697/jeful.2015.6.3.04).

Sahkai, Heete \& Mihkla, Meelis 2017. Pre-focal givenness and accentuation in Estonian. Abrahamsen, Jardar Eggesbö \& Koreman, Jacques \& van Dommelen, Wim A. (toim). Nordic Prosody. Proceedings of the XIIth Conference, Trondheim 2016. Frankfurt am Main: Peter Lang Edition, lk 127-134 (doi: 10.3726/b11152).

Salveste, Nele 2015. On the pragmatic and semantic functions of Estonian sentence prosody. Doktoritöö. München: Ludwig-Maximilian-Universität München (https://edoc. ub.uni-muenchen.de/18943/1/Salveste_Nele.pdf - 1. november 2017).

Sluijter, Agaath \& van Heuven, Vincent 1996. Acoustic correlates of linguistic stress and accent in Dutch and American English. Proceeding of Fourth International Conference on Spoken Language Processing. ICSLP ‘96, Philadelphia, lk 630-633 (doi: 10.1109/ ICSLP.1996.607440).

Suomi, Kari \& Meister, Einar 2013. F0 comparison of Northern Estonian and Northern Finnish contrastively accented words. Asu, Eva Liina \& Lippus, Pärtel (toim). Nordic Prosody: Proceedings of the XIth Conference, Tartu 2012. Frankfurt am Main: Peter Lang Verlag, lk 383-390.

Suomi, Kari \& Meister, Einar \& Ylitalo, Riikka \& Meister, Lya 2013. Durational patterns in Northern Estonian and Northern Finnish. Journal of Phonetics 41 (1), lk 1-16 (doi: 10.1016/j.wocn.2012.09.001).

Šimko, Juraj \& Aalto, Daniel \& Lippus, Pärtel \& Włodarczak, Marcin \& Vainio, Martti 2015. Pitch, perceived duration and auditory biases: comparison among languages. Wolters, Maria \& Livingstone, Judy \& Beattie, Bernie \& Smith, Rachel \& MacMahon, Mike \& Stuart-Smith, Jan (toim). Proceedings of the 18th International Congress of Phonetic Sciences. Glasgow: University of Glasgow, lk 1-5.

Tamburini, Fabio 2003. Prosodic prominence detection in speech. Proceedings. 7th International Symposium on Signal Processing and its Applications - ISSPA2003, Paris, lk 385-388 (doi: 10.1109/ISSPA.2003.1224721).

Vogel, Irene \& Athanasopoulou, Angeliki \& Pincus, Nadya 2016. Prominence, Contrast, and the Functional Load Hypothesis: An Acoustic Investigation. Heinz, Jeffrey \& Goedemans, Rob \& van der Hulst, Harry (toim). Dimensions of Phonological Stress. Cambridge University Press, lk 123-167. 


\title{
Summary
}

\section{Acoustic correlates of sentence stress in Estonian}

\author{
Meelis Mihkla \\ Senior Research Fellow / Head of Department \\ Institute of the Estonian Language \\ meelis.mihkla@eki.ee
}

\author{
Heete Sahkai \\ Research Fellow \\ Institute of the Estonian Language \\ heete.sahkai@eki.ee
}

Keywords: duration, Estonian, intensity, pitch, sentence stress, spectral emphasis, vowel quality, quantity degree

The study examines the acoustic correlates of sentence stress in Estonian. The data consists of 18 four-word sentences read aloud by nine speakers in answer to three questions eliciting different information structures. The test words include six sets of triplets of words differing minimally in quantity degree. The words occur in three different stress conditions: (i) after narrow focus (the unstressed condition); (ii) as the nuclear accented word in a broad focus sentence (the stressed condition); and (iii) as an emphatically accented narrow focus (used for the purposes of normalisation). The test word is always the third word in the four-word sentence in order to avoid interferences from boundary signals.

The potential correlates under study are the following: (i) the F0 range and peak height of the test word, measured in the test words with a $\mathrm{H}^{*} \mathrm{~L}$ pitch accent respectively as the difference between the F0 maximum of the stressed syllable and the F0 minimum of the unstressed syllable, and as the difference from the mean F0 maximum of the test word in the three stress conditions produced by a speaker; (ii) the duration of the test word in the different stress conditions, measured as the difference from the mean duration of the test word in all three conditions; (iii) the intensity range and the maximal intensity level of the test word; (iv) the values of the F1 and F2 formants as indicators of vowel quality; and (v) the spectral emphasis of the stressed syllable of the test words. The above values were analysed separately for the three quantity degrees in order to determine a potential effect of the prosodic structure of the word on the acoustic realisation of sentence stress. The data was statistically analysed with the Systat software package. The classification power of the different parameters was determined, using linear discriminant analysis.

The strongest correlate of sentence stress turned out to be F0, as was expected, given that sentence stress is phonologically realised as a pitch accent. From the two F0 values, the peak height was the stronger one, with a classification power of $89 \%$, F0 range permitting to classify correctly $76 \%$ of the data. Almost equally strong correlates as the F0 range were the duration and intensity level, classifying correctly respectively $75 \%$ and $73 \%$ of the data. Vowel quality and spectral emphasis did not correlate significantly with sentence stress. The results also revealed an effect of lexical prosody on the acoustic realisation of sentence stress: the lengthening and the rise of the intensity level were the largest in the stressed words of the third (overlong) quantity degree. 